\title{
Detecting Mycobacterium ulcerans in Clinical Specimens from Ghana: Comparative Evaluation of BU-LAMP and IS2404 PCR
}

\section{Enoch Aninagyei ${ }^{*}{ }^{(\mathbb{D}}$, Rufai Tanko $^{2}$ (D) Comfort Dede Tetteh ${ }^{3}$ (D) Kofi Adjei Ntiri ${ }^{4}$ (D), Mathias Dongyele ${ }^{5}$ (D), Alex Boye 6 (D) and Desmond Omane Acheampong ${ }^{7}$ (D)} ${ }^{1}$ Department of Biomedical Sciences, School of Basic and Biomedical Sciences, University of Health and Allied Sciences,
Ghana

${ }^{2}$ New Juabeng Municipal Health Directorate, Koforidua, Ghana

${ }^{3}$ Ga West Municipal Health Directorate, Amasaman, Accra, Ghana

${ }^{4}$ Mayera-Faase Health Centre, Mayera-Faase, Greater Accra Region, Ghana

${ }^{5}$ Ear, Nose and Throat Nursing School, Kumasi, Ashanti Region, Ghana

${ }^{6}$ Department of Medical Laboratory Technology, University of Cape Coast, Ghana

${ }^{7}$ Department of Biomedical Sciences, School of Allied Health Sciences, University of Cape Coast, Ghana

*Corresponding author: Enoch Aninagyei, Department of Biomedical Sciences, School of Basic and Biomedical Sciences, University of Health and Allied Sciences, PMB 31, Ho, Volta Region, Ghana, Tel: +233-244-632496

\begin{abstract}
Background: Conventional and nested polymerase chain reaction (PCR), and loop-mediated isothermal amplification (LAMP) have been used to identify Mycobacterium ulcerans in separate studies and different specimens. However, the sensitivities of these three techniques have not been compared in a single study.
\end{abstract}

Objective: This study compared the performance of two variant PCR techniques and LAMP assays to detect $M$. UIcerans in same clinical specimens.

Methods: Samples were collected from patients suspected of Buruli ulcer disease (BUD) in Southern Ghana. Ulcerative and non-ulcerative forms of the disease were swabbed and aspirated respectively. Insertion sequence 2404 (IS2404) $M$. ulcerans targets were detected in each sample using conventional polymerase chain reaction (PCR), nested PCR and loop-mediated isothermal amplification (LAMP) assay.

Results: In all, 141 suspected BUD patients were sampled (Amasaman, $n=52$; Obom, $n=17$; Paakro, $n=31$; Nkawie, $n=21$ and Tepa, $n=20)$. The reference technique, nested PCR, detected $M$. ulcerans in $122(86.5 \%)$ whereas conventional PCR and BU-LAMP detected $M$. ulcerans in 104 $(73.7 \%)$ and $119(84.4 \%)$ samples respectively. Compared to nested PCR, conventional PCR performed poorly $\left(x^{2}=19.7\right.$, $p<0.01 ; k=0.58 ; \%$ agreement $=86.62)$ while BU-LAMP was as good as nested PCR $\left(x^{2}=0.457, p=0.459 ; k=0.88\right.$; $\%$ agreement $=97.16)$. Sensitivity of conventional PCR and BU-LAMP were $84.6 \%$ (95\% Cl: 76.9-90.4) and 97.5\% (95\% Cl: 92.9-99.5) respectively. BU-LAMP and nested PCR detected $M$. ulcerans in ulcerative forms of the disease and category II lesions better while the three techniques did not differ in sensitivities in other clinical forms and lesion categories.

Conclusion: BU-LAMP assay is very comparable to nested $\mathrm{PCR}$ in detecting $M$. ulcerans from clinical specimens. More importantly, LAMP assay is user-friendly, fast, requires less instrumentation and easy to use in resource-limited laboratory with minimal user training.

\section{Keywords}

Mycobacterium ulcerans, BU-LAMP, Nested-PCR, Conventional PCR, Buruli ulcer, Ghana

\section{Abbreviations}

BUD: Buruli Ulcer Disease; DNA: Deoxyribonucleic Acid; IS: insertion sequence; LAMP: Loop-Mediated Isothermal Amplification; PCR: Polymerase Chain Reaction

Citation: Aninagyei E, Tanko R, Tetteh CD, Ntiri KA, Dongyele M, et al. (2020) Detecting Mycobacterium ulcerans in Clinical Specimens from Ghana: Comparative Evaluation of BU-LAMP and IS2404 PCR. Int J Trop Dis 3:037. doi.org/10.23937/2643-461X/1710037

Accepted: October 17, 2020; Published: October 19, 2020

Copyright: (c) 2020 Aninagyei $\mathrm{E}$, et al. This is an open-access article distributed under the terms of the Creative Commons Attribution License, which permits unrestricted use, distribution, and reproduction in any medium, provided the original author and source are credited. 


\section{Introduction}

Mycobacterium ulcerans causes Buruli ulcer disease (BUD), a tropical skin disease which presents with severe necrosis and chronic cutaneous infection [1]. After $M$. ulcerans inoculation, lesions appear as painless, and mostly ignored by patients [2]. Early stages of the disease present as papules, nodules, plaques and oedema [3]. Which later progresses to ulceration of subcutaneous layers and bones [4], if treatment is delayed.

Due to the disfiguration and lifelong loss of mobility associated with the disease [5], early diagnosis with sensitive, rapid, user-friendly and cheap technique is important. In view of the foregoing, several diagnostic techniques have been developed to improve diagnosis of BUD. Notwithstanding, rapid diagnosis of the disease using sensitive techniques has not been achieved due to various demerits associated with current testing methods. The most common diagnostic methods are Ziehl-Neelson microscopy technique [6], cultivation of the bacilli [7] and molecular detection of insertion sequence 2404 (IS2404) using either polymerase chain reactions (PCR) [8] and/or loop-mediated isothermal amplification techniques (LAMP) [9]. Microscopic detection and culture of $M$. ulcerans are very specific, however these techniques are slow (positive culture obtainable in 6-12 weeks and in some cases up to 36 weeks) and of low sensitivity (approx. 40\% for microscopy and $20-60 \%$ for culture) $[6,10,11]$. PCR on the other hand is very sensitive [8] but the processes involved are time consuming, delaying results for clinical decision. Again, it is not easily exploited in laboratories of developing countries where the disease is endemic [12]. A quick method for diagnosis of BUD has been developed, based on the loop mediated isothermal amplification (BU-LAMP) technique. As it stands now, three different LAMP assays for laboratory confirmation of BUD have been published [13]. The assay described by de Souza, et al. [9] targeted the enoyl reductase gene of $M$. ulcerans. Enoyl reductase gene is involved in mycolactone synthesis, the most important virulence factor in BUD pathogenesis. However, technical validation of the assay was conducted only on a limited number of samples. Deployment of this assay on a large scale, with samples collected from different locations and from different clinical forms of the disease is essential towards point-of-care application of the LAMP assay. Hence, this study was designed to compare the efficiency of BU-LAMP to the conventional and nested PCR. Even though these techniques have been piloted in separate studies, their sensitivities have not been evaluated using the same set of samples.

\section{Methods}

\section{Study sites}

Clinical specimens used in this study were collected from major Buruli ulcer clinics in Southern Ghana. Namely, Ga West Municipal Hospital in Amasaman,
Obom Health centre in Obom (Greater Accra Region), Paakro Health Centre in Paakro (Eastern Region), Nkawie-Toase Hospital in Nkawie and Tepa Government Hospital in Tepa (both in Ashanti Region). These health facilities serve as referral sites for Buruli ulcer disease from nine of 16 regions in Ghana.

\section{Sampling techniques}

Samples were collected from both ulcerative and non-ulcerative forms of the disease. Non-ulcerative and ulcerative lesions were aspirated using fine needle and swabbed using sterile swab sticks respectively. Both fine needle aspirates and swabs tips with necrotic tissues were put in Eppendorf tubes containing $1 \mathrm{~mL}$ of PANTA (polymyxin B, amphotericin B, nalidixic acid, trimethoprim and azlocillin) transport medium. All samples were sent to Bacteriology Department of Noguchi Memorial Institute for Medical Research, University of Ghana for molecular analysis. Demographic parameters as well as clinical forms and categories of the lesions were also taken.

\section{Inclusion and exclusion criteria}

Suspected BUD patients included in the study were new patients (patients that have never been treated with anti-BUD drugs or have taken anti-BUD drugs for less than 1 month). Patients with category three lesions at critical sites such as eye, genitals, breast, joints and osteomyelitis were excluded in this study.

\section{Place of laboratory work}

DNA extraction, polymerase chain reactions and loop-mediated isothermal amplification assays for all samples were done in the Department of Bacteriology, Noguchi Institute for Medical Research, University of Ghana, Legon-Accra.

\section{DNA extraction using the modified Boom's method}

DNA was extracted and purified based on the protocol described by Ablordey, et al. [14]. In brief, Portions $250 \mu \mathrm{l}$ of the sample suspensions were lysed with 250 $\mu$ of lysis buffer (1.6 M GuHCl, $60 \mathrm{mM}$ Tris pH 7.4, 1\% Triton X-100, 60 mM EDTA, Tween-20 10\%), $50 \mu$ l Proteinase- $\mathrm{K}$ and $250 \mu \mathrm{l}$ glass beads. The mixtures were incubated horizontally at $200 \mathrm{rpm}$ at $60^{\circ} \mathrm{C}$ overnight. To capture the DNA, $40 \mu \mathrm{l}$ of diatomaceous earth solution (10g diatomaceous earth obtained from Sigma-Aldrich Chemie $\mathrm{GmbH}$ in $50 \mathrm{ml}$ of $\mathrm{H}_{2} \mathrm{O}$ containing $500 \mu \mathrm{l}$ of $37 \%$ (wt/vol) $\mathrm{HCl}$ ) was added to the suspensions and incubated at $37{ }^{\circ} \mathrm{C}$ with shaking $(200 \mathrm{rpm})$ for $60 \mathrm{~min}$. The mixtures were centrifuged at $14,000 \mathrm{rpm}$ for $10 \mathrm{sec}$. and the resulting pellets washed twice with $900 \mu \mathrm{l}$ of $70 \%$ ethanol $\left(2-8^{\circ} \mathrm{C}\right)$ followed by $900 \mu \mathrm{l}$ of acetone. The pellets were dried at $50{ }^{\circ} \mathrm{C}$ for $20 \mathrm{~min}$ and resuspended in $100 \mu \mathrm{l}$ milli Q purified water and centrifuged at 14,000 rpm for $10 \mathrm{sec}$. The purified DNA was used as templates for both IS2404 nested-PCR and LAMP assays to detect M. ulcerans. 


\section{Conventional PCR}

Conventional PCR master mix per sample was prepared by adding the constituent reagents as follows; $2 \mu \mathrm{L}$ Qiagen buffer, $2 \mu \mathrm{L}$ Q solution, $1.2 \mu \mathrm{L} \mathrm{MgCl}$ ( 25 $\mathrm{mmol} / \mathrm{L}$ ), $2 \mu$ leach deoxynucleoside triphosphate (200 $\mu \mathrm{L}), 1 \mu \mathrm{L}$ forward primer $(0.5 \mu \mathrm{mol} / \mathrm{L}), 1 \mu \mathrm{L}$ reverse primer $(0.5 \mu \mathrm{mol} / \mathrm{L}), 0.2 \mu \mathrm{L}$ Taq DNA polymerase (HotstarTaq plus), $9 \mu \mathrm{L}$ nuclease free water, and approximately $50 \mathrm{ng}$ of DNA. The primer sets used were MU1 (5'-GATCAA GCGTTCACGAGTGA-3') and MU2 (5'-GGCAGTTACTTCACTGCACA-3') [15]. The PCR reaction mixture was spun shortly to remove water droplets from the inner wall of the PCR tube and inserted into a thermocycler for 40 cycles of DNA denaturation at $96{ }^{\circ} \mathrm{C}$, primer annealing at 60 ${ }^{\circ} \mathrm{C}$, and oligonucleotide extension at $68{ }^{\circ} \mathrm{C}$. PCR products were electrophoresed in a $1.5 \%$ Tris-acetate- EDTA TAE $(\mathrm{pH}=8.0)$ agarose gel with ethidium bromide. The amplicon sizes were estimated by comparison with DNA ladder (Invitrogen, USA) and visualized using Kodak Gel logic 100 imaging system.

\section{IS2404 nested PCR reaction}

Due to unavailability of IS2404 GPCR, nested PCR was used as reference technique to which all other techniques were compared. The IS2404 sequence was amplified in a $30 \mu \mathrm{l}$ reaction mixture comprising 15.5 $\mu \mathrm{l}$ nuclease free water, $3 \mu \mathrm{l} \mathrm{PCR}$ buffer, $6.0 \mu \mathrm{l}$ Q-solution, $2.0 \mu \mathrm{l}$ dNTPs, $0.1 \mu \mathrm{l}$ Hotstar Taq DNA pol, $0.3 \mu \mathrm{l}$ each of pGp1 (pGp1: 5'-AGGGCAGCGCGGTGATACGG-3') and pGp2 (pGp2: 5'- CAGTGGATTGGTGCCGATCGAG-3') primers and $3 \mu \mathrm{I}$ DNA extract. The first run PCR reaction was done based on these amplification conditions; initial denaturation at $95^{\circ} \mathrm{C}$ ( 15 minutes) and 40 cycles of denaturation, annealing and extension at $94{ }^{\circ} \mathrm{C}, 64$ ${ }^{\circ} \mathrm{C}$ and $75^{\circ} \mathrm{C}$ respectively. The second run of the 152404 (nested) PCR was performed by using $1 \mu$ l of the first run PCR amplicons as the template DNA and $24 \mu$ of master mix. The master mix for the nested reaction was the same as that for the first run PCR except that primer set $p G p 1$ and $p G p 2$ were replaced with the primer set $p G p 3$ (5'-GGCGCAGATCAACTTCGCGGT-3') and pGp4 (5'-CTGCGTGGTGCTTTACGCGC-3') with the same volume. The same PCR amplification condition was used for the nested PCR except 35 cycles of denaturation, annealing and extension. The primers used have been previously used by Ablordey, et al. [14].

\section{BU-LAMP reaction}

The BU-LAMP reaction was made in $25.0 \mu \mathrm{L}$ volume made up of $12.5 \mu \mathrm{l}$ of reaction mix, $1 \mu \mathrm{L}$ of fluorescent detector, $2.6 \mu \mathrm{L}$ of primer mix (FIP: 5'-GCATCTCCGGCCACCCCAACGCCCAACGACCGCTA-3'; BIP: 5'-GTGGTGGGCCCCTGGGAAACCGCTGTCGAACTGTGC-3'; F3: 5'-ACGGATCGTCGAGGATGG-3'; B3: 5'-GCGCCAGGTCCCTTGA-3'; FLP: 5'-GAGCCTGCTGGGCGGTC-3'; BLP: 5'-CATATCCCACCCTGGTG-3'), $1 \mu \mathrm{L}$ of Bst DNA poly- merase (Eiken Chemical, Japan), $2.9 \mu \mathrm{L}$ of nuclease free distilled water (Promega, USA) and $5 \mu$ l of the DNA extract in $0.2 \mathrm{ml}$ microAmp ${ }^{\mathrm{TM}}$ tubes (Applied Biosystems, Singapore). The DNA amplification was done by incubating the reaction mixture on a heating block at a temperature of $65^{\circ} \mathrm{C}$ for 1 hour and the Bst DNA polymerase was inactivated at $80^{\circ} \mathrm{C}$ for 5 minutes. The BU-LAMP primers used were designed by de-Souza, et al. [9]. The final reactions were determined by visual examination of the final colour production. A final greenish yellow colour development signified a positive reaction and a light brown final colour signified a negative reaction.

\section{Quality control for molecular techniques}

For every batch of 20 DNA isolation from clinical samples, two tubes of nucleic free water and two isolates of culture positive samples, found to be positive by IS2404 $P C R$, were used as negative and positive extraction controls respectively. Initial screening found the negative and positive controls negative and positive respectively before that batch of DNA from clinical samples were further processed. During the amplification phase of the techniques, another two tubes of nucleic free water and two IS2404 positive culture samples were used as respective negative and positive amplification controls. A respective corresponding negative and positive amplifications outcome validated all PCR and LAMP assays.

\section{Data analysis}

Data were analysed using SPSS Version 24 (Chicago, IL, USA). Differences in categorical data were determined using Chi square whilst Chi square goodness of fit was used to compare the performance of conventional PCR and BU-LAMP to nested PCR. Finally, sensitivities, specificities, positive and negative predictive values and their respective $95 \%$ confidence intervals as well as the inter-diagnostic technique test of agreement were determined based on Bayesian model. In all these analysis, significant levels were determined at $p<0.05$.

\section{Results}

\section{Study sites, age and gender distributions of the patients}

A total of 141 suspected Buruli ulcer cases were sampled from the five study sites from August 2014 to May 2016. In absolute terms, majority of the cases were sampled from Ga West Municipal Hospital (46, 32.6\%), Amasaman while minority of the cases sampled were seen in Obom Health Centre (17, 12.0\%), Obom. Majority of the suspected cases were males $(65.9 \%)$ and patients aged less than 19 years (36.9\%). In all study areas, $80.0 \%$ or more of the suspected cases were confirmed to be infected with Buruli ulcer disease (BUD). High prevalence of BUD was also seen in both males and females with patients aged 0-19 years disproportionally affected (94.2\%) (Table 1). 
Table 1: Distribution of Buruli ulcer cases by study sites, gender and age group of patients (yrs).

\begin{tabular}{|l|l|l|l|}
\hline Variable (number of suspected BUD cases) & $\begin{array}{l}\text { Number (\%) confirmed } \\
\text { positive by nested PCR }\end{array}$ & $\begin{array}{l}\text { Number (\%) confirmed } \\
\text { negative by nested PCR }\end{array}$ & p-value \\
\hline Study site & $46(88.5 \%)$ & $6(11.5 \%)$ \\
\hline Ga West Hospital $(n=52)$ & $19(90.5 \%)$ & $2(9.5 \%)$ \\
\hline Nkawie-Toase Hospital $(n=21)$ & $16(94.1 \%)$ & $1(5.9 \%)$ \\
\hline Obom Health Centre $(n=17)$ & $25(80.6 \%)$ & $6(19.4 \%)$ \\
\hline Paakro Health Centre $(n=31)$ & $16(80.0 \%)$ & $4(20.0 \%)$ \\
\hline Tepa Govt Hospital $(n=20)$ & & & 0.201 \\
\hline Gender & $83(89.2 \%)$ & $10(10.8 \%)$ \\
\hline Male $(n=93)$ & $39(81.3 \%)$ & $9(18.7 \%)$ \\
\hline Female $(n=48)$ & & \\
\hline Age group (yrs.) & $49(94.2 \%)$ & $3(5.8 \%)$ \\
\hline $0-19(n=52)$ & $27(87.1 \%)$ & $4(12.9 \%)$ \\
\hline $20-39(n=31)$ & $37(86.0 \%)$ & $6(13.0 \%)$ \\
\hline $40-59(n=43)$ & $8(80.0 \%)$ & $2(20.0 \%)$ \\
\hline $60-79(n=10)$ & $1(20.0 \%)$ & $4(80.0 \%)$ \\
\hline $80+(n=5)$ & \\
\hline
\end{tabular}

p-values determined by Chi square at $95 \%$ confidence interval.

Table 2: Comparative performance analysis of the diagnostic techniques.

\begin{tabular}{|l|l|l|l|}
\hline Diagnostic Technique & $\begin{array}{l}\text { Positivity Rate } \\
\text { n (\%) }\end{array}$ & $\begin{array}{l}\text { Negativity Rate } \\
\mathbf{n}(\mathbf{\%})\end{array}$ & $\begin{array}{l}\text { Chi square goodness of fit } \\
\mathbf{x}^{\mathbf{2}}(\mathbf{p}-\mathbf{v a l u e})\end{array}$ \\
\hline Nested IS2404 PCR & $122(86.5 \%)$ & $19(13.5 \%)$ & - \\
\hline Conventional IS2404 PCR & $104(73.8 \%)$ & $37(26.25)$ & $19.7(p<0.001)$ \\
\hline BU-LAMP assay & $119(84.4 \%)$ & $22(15.6)$ & $0.547(p=0.459)$ \\
\hline
\end{tabular}

Chi square goodness of fit was determined at $95 \%$ confidence interval.

\section{Clinical forms of the disease, category of lesions and type of samples collected}

Out of the 141 samples collected, $73 \%$ were ulcerative lesions, 16.3 were nodular lesions and $10.6 \%$ were oedematous form of the disease. Per the clinical forms of the disease encountered, swab samples were collected from ulcerative form of the disease while fine needle aspiration was done on the nodular and oedematous forms of the disease (27\%). All the three categories of the disease were encountered; category 1 lesions (single lesions $<5 \mathrm{~cm}$ in diameter [5]) were 64 (45.3\%), category II lesions (single lesions between $5-15 \mathrm{~cm}$ diameter [5]) were 24 (17.0\%) and category III lesions (either a single lesion more than $15 \mathrm{~cm}$ diameter or multiple lesions or lesions at critical sites such as eye, genitals, breast, joints [5]) were 53 (37.6\%).

\section{Positivity rate of the techniques}

Nested PCR detected M. ulcerans in 122 (86.5\%) of the 141 samples tested while conventional PCR and BU-LAMP detected M. ulcerans in 104 (73.8\%) and 119 (84.4\%) samples tested respectively. Compared to nested PCR, the performance of conventional PCR was statistically different $\left(x^{2}=19.7, p<0.01\right)$ while the performance of nested PCR did not differ from BU-LAMP assay $\left(x^{2}=0.457, p=0.459\right)$ (Table 2).

\section{Sensitivity and specificity of the diagnostic tech- niques}

The diagnostic performance of BU-LAMP and conventional PCR to detect $M$. ulcerans using nested PCR results as reference technique are presented in Table 3. The sensitivity of BU-LAMP was higher than conventional PCR even though both techniques were of equal specificity. According to the interpretation of Cohen's kappa values by McHugh [16], there was a strong agreement between nested PCR and BU-LAMP ( $\mathrm{K}=0.88)$ whilst nested PCR agreed with conventional PCR weakly $(\mathrm{K}=$ 0.58).

\section{Analysis of the efficiency of the protocols on clini- cal forms and lesions categorization}

The performance of the three diagnostic techniques to detect $M$. ulcerans in ulcerative forms of the disease was significantly different. The performance of the techniques differed in their ability to detect $M$. ulcerans in ulcerative lesions $\left(x^{2}=9.68, p=0.008\right)$ but not in nodu$\operatorname{lar}\left(x^{2}=1.81, p=0.403\right)$ and oedematous forms of the disease $\left(x^{2}=2.50, p=0.286\right)$. Nested-PCR and BU-LAMP detected $M$. ulcerans in equal number of ulcerative samples so as nodular samples. But BU-LAMP did not detect $M$. ulcerans in oedematous lesion as compared 
Table 3: Diagnostic indices and how nested PCR agreed with Bu-LAMP and conventional PCR.

\begin{tabular}{|l|l|l|}
\hline Indices & BU-LAMP & Conventional PCR \\
\hline True positive & 119 & 104 \\
\hline True negative & 19 & 19 \\
\hline False positive & 0 & 0 \\
\hline False negative & 3 & 19 \\
\hline Sensitivity $(95 \% \mathrm{Cl})$ & $97.5 \%(92.9-99.5 \%)$ & $84.6 \%(76.9-90.4 \%)$ \\
\hline Specificity $(95 \% \mathrm{Cl})$ & $100.0(82.35-100.0)$ & $100.0(82.35-100.0)$ \\
\hline PPV $(95 \% \mathrm{Cl})$ & 100.0 & 100.0 \\
\hline NPV $(95 \% \mathrm{Cl})$ & $86.4 \%(67.4-95.1 \%)$ & $50.00 \%(39.81-60.19 \%)$ \\
\hline Kappa value & $0.88 \%(0.564-0.741)$ & $0.59 \%(0.51-0.69)$ \\
\hline \% agreement & 97.16 & 86.62 \\
\hline
\end{tabular}

Values in parenthesis is $95 \%$ confidence interval.

Table 4: Performance of the techniques on clinical forms and categories of the disease.

\begin{tabular}{|l|l|l|l|l|l|l|l|}
\hline & \multicolumn{2}{|l|}{ Nested IS2404 PCR } & \multicolumn{2}{l|}{ Conventional IS2404 PCR } & BU-LAMP & \\
\hline & $\begin{array}{l}\text { Positive } \\
\mathrm{n}(\%)\end{array}$ & $\begin{array}{l}\text { Negative } \\
\mathrm{n}(\%)\end{array}$ & $\begin{array}{l}\text { Positive } \\
\mathrm{n}(\%)\end{array}$ & $\begin{array}{l}\text { Negative } \\
\mathrm{n}(\%)\end{array}$ & $\begin{array}{l}\text { Positive } \\
\mathrm{n}(\%)\end{array}$ & $\begin{array}{l}\text { Negative } \\
\mathrm{n}(\%)\end{array}$ & $x^{2}(\mathrm{p}$-value) \\
\hline Clinical forms of lesions & & & & & & \\
\hline Ulcer $(\mathrm{n}=103)$ & $89(86.4 \%)^{*}$ & $14(13.6 \%)$ & $74(71.8 \%)$ & $29(28.2 \%)$ & $89(86.4 \%)^{*}$ & $14(13.6 \%)$ & $9.68(0.008)$ \\
\hline Nodule $(\mathrm{n}=23)$ & $20(87.0 \%)$ & $3(13.0 \%)$ & $17(74.0 \%)$ & $6(26.0 \%)$ & $20(87.0 \%)$ & $3(13.0 \%)$ & $1.81(0.403)$ \\
\hline Oedema $(\mathrm{n}=15)$ & $13(86.7 \%)$ & $2(13.3 \%)$ & $13(86.7 \%)$ & $2(13.3 \%)$ & $10(66.7 \%)$ & $5(33.3 \%)$ & $2.50(0.286)$ \\
\hline Categorization of lesions & & & & & & \\
\hline Category $1(\mathrm{n}=64)$ & $58(90.6)$ & $6(9.4 \%)$ & $55(86.0 \%)$ & $9(14.0 \%)$ & $58(90.6 \%)$ & $6(9.7 \%)$ & $0.96(0.618)$ \\
\hline Category II $(\mathrm{n}=24)$ & $21(87.5)^{*}$ & $3(12.5 \%)$ & $13(54.2 \%)$ & $11(45.8 \%)$ & $21(87.5 \%)^{*}$ & $3(12.5 \%)$ & $6.82(0.033)$ \\
\hline Category III $(\mathrm{n}=53)$ & $43(81.1)$ & $10(18.9 \%)$ & $36(67.9 \%)$ & $17(23.1 \%)$ & $40(75.5 \%)$ & $13(24.5 \%)$ & $2.47(0.290)$ \\
\hline
\end{tabular}

*No significant difference between techniques at significant level of 0.05 . P-values were determined by Chi square at significant level 0.05. Category I lesions are single lesions $<5 \mathrm{~cm}$ in diameter; category II lesions are single lesions between $5-15 \mathrm{~cm}$ diameter; category III lesions are either a single lesion more than $15 \mathrm{~cm}$ diameter or multiple lesions [5].

to the other two techniques. Also, the was differences in the ability of the techniques to detect $M$. ulcerans in category II lesions but nested-PCR and BU-LAMP detected $M$. ulcerans in category II lesions with equal ability. In category I and III lesions, the techniques had equal ability to detect M. ulcerans in their samples (Table 4).

\section{Discussion}

The sensitivity of three molecular techniques for the diagnosis of Buruli ulcer disease (BUD) is reported herein. Nested-PCR detected more infections in the clinical specimens than BU-LAMP and conventional PCR. However, BU-LAMP was superior to conventional PCR. The positivity rates for the techniques reflected in the sensitivities of the techniques. Comparing to nested-PCR, BU-LAMP was more sensitive than conventional PCR. However, the techniques were of equal specificities. Furthermore, nested-PCR performed better on all the categories and clinical forms of the disease. This study presents an alternative to laboratory diagnosis of BUD. Laboratory confirmation of BUD is a better diagnostic option compared to the widely used clinical diagnosis which represents a challenge due to the vast number of other skin infections or conditions that may present symptoms similar to that of BUD [17]. In furtherance to this, World Health Organization (WHO) has directed that all suspected cases of BUD are confirmed in the laboratory [18].

The performance of the three diagnostic techniques to detect $M$. ulcerans in ulcerative forms of the disease significantly differed from the other. While nested-PCR and Bu-LAMP performed very well on ulcerative lesions $\left(x^{2}=9.68, p=0.008\right)$, the techniques were comparable on nodular lesions $\left(x^{2}=1.81, p=0.403\right)$ and oedematous forms of the disease $\left(x^{2}=2.50, p=0.286\right)$. Also, there were differences in the ability of the techniques to detect $M$. ulcerans in category II lesions but nested-PCR and BU-LAMP detected M. ulcerans in category II lesions with equal ability. In category I and III lesions, the techniques had equal ability to detect $M$. ulcerans in their samples. Detection of insertion sequence (IS) elements in Mycobacterium spp have been reported in several studies [19-21]. ISs are species specific, and multiple copies have been detected within one genome, facilitating a highly specific and sensitive detection of the respective pathogens. Ross, et al. [8] first provided a milestone for the PCR-based diagnosis of BUD by identifying an $M$. ulcerans-specific repetitive DNA fragment 
which was later characterized in detail and designated IS2404 [22]. There are about $150-200$ copies of IS2404 per $M$. ulcerans genome [23]. These large copies of IS2404 predestine their application as targets for sensitive molecular amplification tests for M. ulcerans.

On the other hand, loop-mediated isothermal amplification (LAMP) is a molecular method, which is relatively cheaper, simpler and faster compared to the PCR. The LAMP technology has been developed to detect several pathogens such as Trypanosoma species [24], Cryptosporidium species [25], Toxoplasma gondii [26], Babesia microti [27], Taenia species [28], Mycobacterium tuberculosis [29], Plasmodium spp [30] and rift valley fever virus [31]. In this study, LAMP assay was as good as nested PCR. This is because LAMP assays have been found to be very sensitive with the ability to detect as low as 20 - 30 copies of the ISs (about 0.1 to 0.15 genome of M. ulcerans) [32]. The analytical sensitivity of BU-LAMP has been found to be higher than conventional PCR [33] though lower than qPCR [34]. But equipment sophistication and the level of expertise needed to perform qPCR technique makes BU-LAMP an alternative choice in developing countries with resource limited settings. LAMP assays have several advantages over PCR assays. Comparing LAMP to PCR, it was realized that LAMP technology is less expensive in the sense that less instrumentation is required to achieve amplification at isothermal temperatures. Results obtained by LAMP were obtained within 1 hour but in the case of IS2404 PCR, the turnaround time was over 5 hours. Aside high sensitivity of BU-LAMP over PCR, the technique has been found to amplify DNA target from partially processed or unprocessed specimen [35]. Detection of LAMP products was found to be easy due to large amount of dsDNA formed and production of magnesium pyrophosphate allow visual detection of reactions. Considering the nature of LAMP technique, it is highly feasible in the field. These features associated with LAMP have been previously published [24,32,36,37].

In Plasmodium falciparum infections, analytical positive and negative rate of LAMP method was equivalent to that of nested-PCR methods [38]. These reports make LAMP assay a potential technique to replace PCR based techniques as a confirmation technique for infectious agents. Due to the specific nature of the action of LAMP primers, the amount of DNA produced is considerably higher than PCR based amplification. The corresponding release of pyrophosphate results in visible turbidity which allows easy visualization of amplification products [39]. LAMP has been observed to be less sensitive than PCR to inhibitors in complex samples such as blood, possibly due to the use of a different DNA polymerase (Bst DNA polymerase rather than Taq polymerase as in $P C R)$. Several reports have described successful detection of pathogens from minimally processed samples $[40,41]$. This feature of LAMP may be useful in low-re- source or field settings where a conventional DNA or RNA extraction prior to diagnostic testing may be impractical [42]. Also LAMP technique has been evaluated for point-of-care use to detected several pathogens [4345]. Therefore, LAMP has the potential to be used as a point-of-care technique to detect $M$. ulcerans both in the laboratory and in the field.

\section{Conclusion}

This study has demonstrated that BU-LAMP is as good as nested PCR, hence it can be used as a reliable molecular technique to detect $M$. ulcerans infections from clinical samples. It is recommended that LAMP based assays be usedat facilities in endemic communities to detect $M$. ulcerans in suspected lesions because it promised to perform well in resource-limited laboratories. Suffice it to say, LAMP assays have been found to be very cheap, user-friendly, rapid, highly sensitive and above all easy to read amplification reactions.

\section{Acknowledgments}

Authors want to acknowledge the administrators and medical directors of Ga West Hospital, Nkawie-Toase Hospital, Obom Health Centre, Paakro Health Centre and Tepa Government Hospital. Also the role of the respective district disease control officers in identification of the cases and the various roles played by the laboratory managers in charge of the various hospital facilities with respect to this study are appreciated. Finally, authors are thankful to Noguchi Institute for Medical Research, Accra, Ghana for providing facilities to carry out the laboratory work. We are also grateful to Dr D. K. De-Souza and Dr Anthony Ablordey for facilitating the acquisition of the reagents and other consumables used in this study. Finally, we are thankful to Prof Alexander Debrah for supervising this study.

\section{Source of Funding}

This work was funded from authors own resources.

\section{References}

1. Fyfe JAM, Lavender CJ, Handasyde KA, Legione AR, O'Brien CR, et al. (2010) A major role for mammals in the ecology of Mycobacterium ulcerans. PLoS Negl Trop Dis 4: e791.

2. Asiedu K, Sherpbier R, Raviglione MC, WHO Global Buruli Ulcer Initiative (2000) Buruli ulcer: Mycobacterium ulcerans Infection. World Health Organization, Geneva, Switzerland, $1-118$.

3. Bamberger D, Jantzer N, Leidner K, Arend J, Efferth T (2011) Fighting mycobacterial infections by antibiotics, phytochemicals and vaccines. Microbes Infect 13: 613-623.

4. Silva MT, Portaels F, Pedrosa J (2009) Pathogenetic mechanisms of the intracellular parasite Mycobacterium ulcerans leading to Buruli ulcer. Lancet Infect Dis 9: 699-710.

5. Agbenorku P, Edusei A, Agbenorku M, Diby T, Nyador E, et al. (2012) Buruli-ulcer induced disability in Ghana: A Study at Apromase in the Ashanti Region. Plast Surg Int 752749. 
6. Phillips C, Horsfield C, Kuijper S, Lartey A, Tetteh I, et al. (2005) Sensitivity of PCR targeting the IS2404 insertion sequence of Mycobacterium ulcerans in an assay using punch biopsy specimens for diagnosis of buruli ulcer. J Clin Microbial 43: 3650-3656.

7. Portaels F, Aguiar J, Fissette K, Fonteyne PA, De Beenhouwer $\mathrm{H}$, et al. (1997) Direct detection and identification of Mycobacterium ulcerans in clinical specimens by PCR and oligonucleotide-specific capture plate hybridization. J Clin Microbiol 35: 1097-1100.

8. Ross BC, Marino L, Oppedisano F, Edwards R, Robins-Browne RM, et al. (1997) Development of a PCR assay for rapid diagnosis of Mycobacterium ulcerans infection. $J$ Clin Microbiol 35: 1696-1700.

9. De-Souza DK, Quaye C, Mosi L, Addo P, Boakye DA (2012) A quick and cost effective method for the diagnosis of Mycobacterium ulcerans infection. BMC Infect Dis 12: 8-15.

10. King $\mathrm{CH}$, Ashford DA, Dobos KM, Whitney EA, Raghunathan PL, et al. (2001) Mycobacterium ulcerans infection and Buruli ulcer disease: Emergence of a public health dilemma. In: Scheld WM, Craig WA, Hughes JM, Emerging infections. A Soc Microbiol Press, Washington, 9: 137-152.

11. Buntine J, Kimball C (2001) Buruli ulcer: Management of Mycobacterium ulcerans disease: A manual for health care providers. World Health Organization 4.

12. Monteiro L, Bonnemaison D, Vekris A, Petry KG, Bonnet J, et al. (1997) Complex polysaccharides as PCR inhibitors in feces: Helicobacter pylori model. J Clin Microbiol 35: 995998.

13. Beissner M, Phillips RO, Battke F, Bauer M, Badziklou K, et al. (2015) Loop-mediated isothermal amplification for laboratory confirmation of buruli ulcer disease-towards a pointof-care test. PLoS Negl Trop Dis 9: e0004219.

14. Ablordey A, Amissah DA, Aboagye IF, Hatano B, Yamazaki $\mathrm{T}$ (2012) Detection of Mycobacterium ulcerans by the loop mediated isothermal amplification method. PLoS Negl Trop Dis 6: e1590.

15. Lavender CJ, Fyfe JAM (2013) Direct detection of Mycobacterium ulcerans in clinical specimens and environmental samples. Methods Mol Biol 943: 201-216.

16. McHugh ML (2012) Interrater reliability: The kappa statistic. Biochem Med (Zagreb) 22: 276-282.

17. Semret M, Koromihis G, MacLean JD, Libman M, Ward BJ (1999) Mycobacterium ulcerans infection (Buruli ulcer): First reported case in a traveller. Am J Trop Med Hyg 61: 689-693.

18. World Health Organization (2008) Buruli ulcer: Progress report, 2004-2008. Wkly Epidemiol Rec 17: 145-154.

19. Hermans PW, van Soolingen D, Dale JW, Schuitema AR, McAdam RA, et al. (1990) Insertion element IS986 from Mycobacterium tuberculosis: A useful tool for diagnosis and epidemiology of tuberculosis. J Clin Microbiol 28: 20512058.

20. Thierry D, Brisson-Noel A, Vincent-Levy-Frebault V, Nguyen S, Guesdon JL, et al. (1990) Characterization of a Mycobacterium tuberculosis insertion sequence, IS6110, and its application in diagnosis. J Clin Microbiol 28: 2668-2673.

21. Kang TJ, Kim SK, Lee SB, Chae GT, Kim JP (2003) Comparison of two different PCR amplification products (the $18-k D a$ protein gene vs. RLEP repetitive sequence) in the diagnosis of Mycobacterium leprae. Clin Exp Dermatol 28: 420-424.
22. Stinear T, Ross BC, Davies JK, Marino L, Robins-Browne $\mathrm{RM}$, et al. (1999) Identification and characterization of IS2404 and IS2606: Two distinct repeated sequences for detection of Mycobacterium ulcerans by PCR. J Clin Microbiol 37: 1018-1023.

23. Doig KD, Holt KE, Fyfe JA, Lavender CJ, Eddyani M, et al. (2012) On the origin of Mycobacterium ulcerans, the causative agent of Buruli ulcer. BMC Genomics 13: 258.

24. Kuboki N, Inoue N, Sakurai T, Di Cello F, Grab DJ, et al. (2003) Loop-mediated isothermal amplification for detection of African trypanosomes. J Clin Microbiol 41: 5517-5524.

25. Karanis $P$, Thekisoe $O$, Kiouptsi K, Ongerth J, Igarashi I, et al. (2007) Development and preliminary evaluation of a loop-mediated isothermal amplification procedure for sensitive detection of Cryptosporidium oocysts in fecal and water samples. Appl Environ Microbiol 73: 5660-5662.

26. Sotiriadou I, Karanis P (2008) Evaluation of loop-mediated isothermal amplification for detection of Toxoplasma gondii in water samples and comparative findings by polymerase chain reaction and immunofluorescence test (IFT). Diagn Microbiol Infect Dis 62: 357-365.

27. Guan G, Chauvin A, Luo J, Inoue N, Moreau E, et al. (2008) The development and evaluation of a loop-mediated isothermal amplification (LAMP) method for detection of Babesia spp. infective to sheep and goats in China. Exp Parasitol 120: $39-44$.

28. Nkouawa A, Sako Y, Nakao M, Nakaya K, Ito A (2009) Loop- mediated isothermal amplification method for differentiation and rapid detection of Taenia species. J Clin Microbiol 47: 168-174.

29. Tomotada I, Toshiaki S, Kozaburo H (2003) Loop-mediated isothermal amplification for direct detection of Mycobacterium tuberculosis Complex, M. avium, and M. intracellularein Sputum Samples. J Clin Microb 41: 2616-2622.

30. Aninagyei E, Smith-Graham S, Boye A, Egyir-Yawson A, Acheampong DO (2019) Evaluating 18s-rRNA LAMP and selective whole genome amplification (sWGA) assay in detecting asymptomatic Plasmodium falciparum infections in blood donors. Malar J 18: 214

31. Peyrefitte CN, Boubis L, Coudrier D, Bouloy M, Grandadam M, et al. (2008) Real-time reverse-transcription loop-mediated isothermal amplification for rapid detection of rift valley fever virus. J Clin Microbiol 46: 3653-3659.

32. Njiru ZK, Yeboah-Manu D, Stinear TP, Fyfe JAM (2012) Rapid and sensitive detection of Mycobacterium ulcerans by use of a loop-mediated isothermal amplification test. $\mathrm{J}$ Clin Microbiol 50: 1737-1741.

33. Siegmund V, Adjei O, Racz P, Berberich C, Klutse E, et al. (2005) Dry reagent-based PCR as a novel tool for laboratory confirmation of clinically diagnosed Mycobacterium ulcerans-associated disease in areas in the tropics where M. ulceransis endemic. J Clin Microbiol 43: 271-276.

34. Fyfe JAM, Lavender CJ, Johnson PDR, Globan M, Sievers A, et al. (2007) Development and application of two multiplex real-time PCR assays for the detection of Mycobacterium ulcerans in clinical and environmental samples. Appl Environ Microbiol 73: 4733-4740.

35. Kaneko H, Kawana T, Fukushima E (2007) Tolerance of loop-mediated isothermal amplification to a culture medium and biological substances. J Biochem Biophys Methods 70: 499-501.

36. Poon LLM, Wong BWY, Ma EHT, Chan KH, Chow LMC, et al. (2006) Sensitive and inexpensive molecular test for 
falciparum malaria: Detecting Plasmodium falciparum DNA directly from heat-treated blood by loop-mediated isothermal amplification. Clin Chem 52: 303-306.

37. Notomi T, Okayama H, Masubuchi H, Yonekawa T, Watanabe K, et al. (2000) Loop-mediated isothermal amplification of DNA. Nucleic Acids Res 28: E63-E65.

38. Imai K, Tarumoto N, Misawa K, Runtuwene LR, Sakai J, et al. (2017) A novel diagnostic method for malaria using loop-mediated isothermal amplification (LAMP) and Min$I \mathrm{~N}^{\mathrm{TM}}$ nanopore sequencer. BMC Infect Dis 17: 621.

39. Ngotho M, Kagira JM, Gachie BM, Karanja SM, Waema $\mathrm{MW}$, et al. (2015) Loop mediated isothermal amplification for detection of Trypanosoma brucei gambiense in urine and saliva samples in nonhuman primate model. BioMed Res Int 2015: 867846.

40. Mori Y, Kitao M, Tomita N, Notomi T (2004) Real-time turbidimetry of LAMP reaction for quantifying template DNA. J Biochem Biophys Methods 59: 145-157.

41. Curtis KA, Rudolph DL, Owen SM (2008) Rapid detection of HIV-1 by reverse-transcription, loop-mediated isothermal amplification (RT-LAMP). J Virol Methods 151: 264-270.

42. Sattabongkot J, Tsuboi T, Han ET, Bantuchai S, Buates S (2014) Loop-mediated isothermal amplification assay for rapid diagnosis of malaria infections in an area of endemicity in Thailand. J Clin Microbiol 52: 1471-1477.

43. Serra-Casas E, Manrique P, Ding XC, Carrasco-Escobar G, Alava F, et al. (2017) Loop-mediated isothermal DNA amplification for asymptomatic malaria detection in challenging field settings: Technical performance and pilot implementation in the Peruvian Amazon. PLoS One 12: e0185742.

44. de Paz HD, Brotons P, Munoz-Almagro C (2014) Molecular isothermal techniques for combating infectious diseases: Towards low-cost point-of-care diagnostics. Expert Rev Mol Diagn 14: 827-843.

45. Niemz A, Ferguson TM, Boyle DS (2011) Point-of-care nucleic acid testing for infectious diseases. Trends Biotechnol 29: $240-250$. 